\title{
Schemes for the Regional Allocation of Emission Allowances under Stringent Global Climate Policy
}

\author{
Tom Kober, Bob van der Zwaan and Hilke Rösler
}

\begin{abstract}
In this chapter we investigate burden-sharing regimes for the allocation of greenhouse gas emission reduction obligations under a $2{ }^{\circ} \mathrm{C}$ long-term climate policy framework, and present our findings derived from an integrated energyeconomy-climate assessment. In our analysis we focus on two different allocation schemes: a per-capita-based scheme, and a scheme aiming at equalising the climate policy costs among the world regions with respect to their economic capability. We find that, under a per capita based burden-sharing scheme, the amount of carbon certificates traded on the carbon market yields a cumulative capital transfer of 20 trillion US \$ between 2020 and 2050, which is on average 680 billion US\$/year. The main certificate selling regions are Africa and India and the main buyers South America and the Middle East. Conversely to the per capita based scheme, a burdensharing regime that aims at equalising regional climate policy costs leads to a cumulative carbon market capita flow until 2050 of about one quarter with average annual certificate transactions worth 180 billion US\$/year, with China and Other Developing Asia being the major certificate sellers and Western Europe the main buyer. Comparing both burden-sharing schemes with regard to the compensation of non-OECD countries' climate change mitigation efforts via revenues from the global carbon certificate market reveals an advantage of the scheme based on climate policy costs over the per capita scheme, because the policy cost related
\end{abstract}

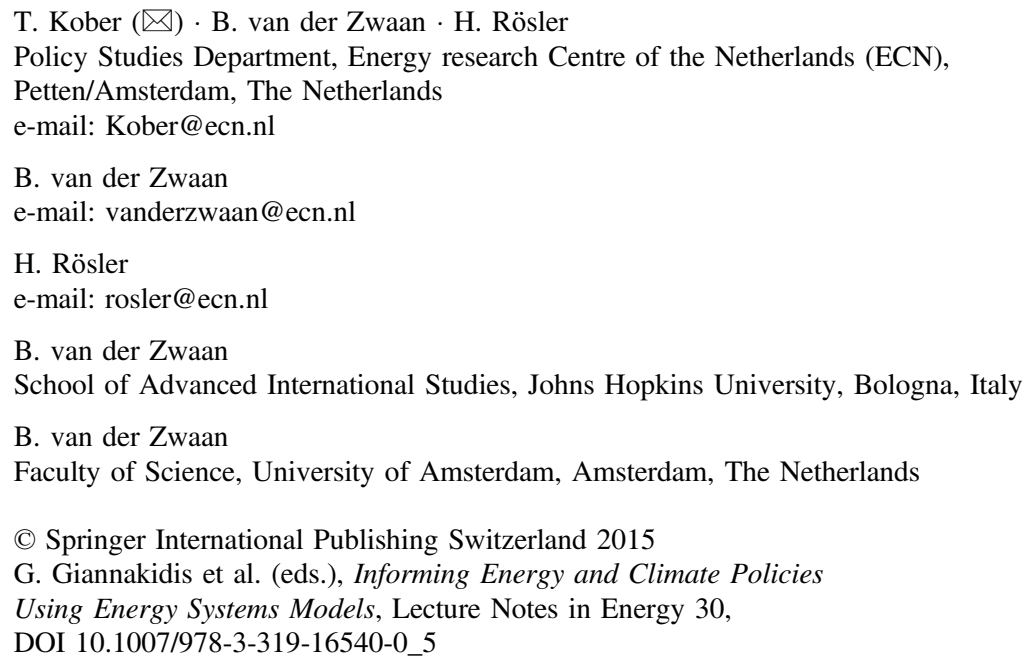


scheme covers $12 \%$ of the non-OECD's climate policy costs of the first half of this century, whereas $4 \%$ under the per capita scheme only.

\section{Introduction}

At the 19th Conference of the Parties (COP-19) of the United Nations Framework Convention on Climate Change (UNFCCC) in 2013 in Warsaw governments decided on further important steps towards a new binding climate change agreement as successor to the Kyoto Protocol. To reach such an agreement policy makers from developed and developing countries will have to negotiate their countries' contribution to the world's climate change efforts taking an equitable allocation of emission reduction obligations into account.

In this chapter we present our work on the cost and carbon certificate trade impacts of two different regimes of inter-regional burden-sharing for the allocation of GHG emission reduction obligations needed to reach stringent global climate change stabilisation. This work, among other research topics, was conducted in the context of the LIMITS project which focussed on the main world regions. ${ }^{1}$ Project results regarding burden-sharing schemes are described as a cross-model comparison study in Tavoni et al. (2013) and for one model in particular in Kober et al. (2014). Compared to the latter publication, this chapter reports more regionally detailed results and provides additional insights for selected countries as to the implications of the different burden-sharing schemes.

We focus our investigation on the distribution of emission allowances and carbon certificate trade effects, as well as carbon market capital flows emanating from the introduction of equitable burden-sharing between regions that undertake collective effort in mitigating global climate change. In Sect. 2 we provide a brief characterisation of the model that we apply, as well the approach and main assumptions used. In Sect. 3 we highlight our main results regarding the main dynamics of the two emission allocation schemes analysed here, including their main differences in terms of certificate trade and carbon market capital flow. In Sect. 4 we report our overall conclusions and reflect upon these in the light of implications for policy makers.

\footnotetext{
1 The LIMITS project was funded by the European Union Seventh Framework Programme FP7/ 2007-2013 under grant agreement no. 282846. Further information on the project is available under www.feem-project.net/limits.
} 


\section{Approach and Socio-economic Assumptions}

The analysis of regional burden-sharing schemes under stringent climate policy control is conducted through a scenario analysis using a global energy system model.

\subsection{TIAM-ECN Energy System Model}

TIAM-ECN is the global TIMES Integrated Assessment Model (TIAM) of the Energy research Centre of the Netherlands (ECN). Its general structure is similar to the ETSAP-TIAM model, as well as the linear optimisation algorithm, in which the total discounted energy system costs are minimised over whole time horizon until 2100. For its 15 regions it contains the abstracted structure of the entire energy economy from resource extraction to energy end use. It features many regionspecific details associated to energy resource availability, conversion and demand. As a technology-rich bottom-up model, it contains many possible fuel transformation and energy supply pathways, and encompasses technologies based on fossil, nuclear and renewable energy resources. According to the technologies' economic and energy system constraints the models determines the most cost-efficient energy transformation pathways in order to satisfy energy demand. Regarding the representation of GHG emission reductions, the model covers abatements options for carbon dioxide $\left(\mathrm{CO}_{2}\right)$, methane $\left(\mathrm{CH}_{4}\right)$ and nitrous oxide $\left(\mathrm{N}_{2} \mathrm{O}\right)$ related to energy conversion, industrial processes and other GHG emission sources, such as agricultural activities. More detailed model descriptions and examples of the application of TIAM-ECN can be found in Rösler et al. (2011, 2014), Keppo and van der Zwaan (2012), van der Zwaan et al. (2013a) and Kober et al. (2014), as well as several references therein. Although the model has been applied to the time horizon to 2100 in order to reflect the very long-term dynamics of selected GHG emissions, we focus our investigation around burden-sharing schemes on the first half of this century as this period better corresponds to the scope of the current climate policy debate.

The demand of useful energy in TIAM-ECN is derived based on socio-economic parameters. For the global development of the gross domestic product (GDP) ${ }^{2}$ we assume more than a tripling of over four decades, from 68 trillion US\$ in 2010 to 247 trillion US\$ in 2050 while the world population grows to 9 billion persons in 2050. This population development is based on the medium fertility projections of the United Nations (UN 2011), with a particular strong growth in Africa, India and Other Developing Asia with a population in 2050 of 2.1, 1.7 and 1.4 billion respectively. China's population is expected to peak at 1.4 billion people around

\footnotetext{
${ }^{2}$ GDP is expressed in terms of purchasing power parity (PPP) and monetary values in US\$ (2005), if not indicated otherwise.
} 
2025 , and to decline thereafter to 1.3 billion people in 2050. For most of the countries of the Organisation for Economic Cooperation and Development (OECD) the population remains comparably stable, with a total average increase of $0.1 \% /$ year for the period 2010-2100. The number of households, which has an impact on the demand for space heating for instance, is assumed to increase more rapidly than the population due to changes of the living patterns towards smaller household sizes. The total number of households doubles from 2 billion to 4 billion households between 2010 and 2050. Further model assumptions and a description of model input data, including the availability of future energy technology, can be found in Kriegler et al. (2013), van der Zwaan et al. (2013b) and Kober et al. (2014).

\subsection{Burden-Sharing Regimes}

An energy system that allows the provision of energy services while attaining deep GHG emission reductions in order to mitigate climate change is more costly compared to a system not subjected to GHG emission reductions if one neglects damages to the energy system due to climate change. To achieve stringent climate policy targets as cost-effective as possible, substantial expenditures are required in all regions worldwide, independent of their economic development status. These additional cost vary across regions due to various reasons, and in some regions there may exist more low-cost GHG abatement options than in others. To unlock the world's least-cost GHG mitigation options, some regions may need to disproportionally contribute to global climate change mitigation efforts, for which they would need to be compensated. Regional compensation mechanisms, also named burden-sharing schemes, aim to establish a more equitable distribution of the financial burdens associated with climate change mitigation by shifting costs attributed to GHG emission reduction across regions. Examples of burden-sharing mechanisms are the emission reduction targets of the member states of the European Union (EU), which are subjected to emissions not covered by the European Emissions Trading Scheme (EU 2013), and the intra-EU burden sharing of the 2010 EU target under the Kyoto Protocol based on the "Triptych approach" (Phylipsen and Blok 2013). Burden-sharing schemes that have different indicators in common, which can be based on socio-economic variables, energy- and emission's parameters and/or cost factors, are used to formulate the equity principle underlying each scheme and to determine a region-specific allocation of emission allowances. Through exchange of these allowances on a carbon certificate market, both costefficient allocation of GHG emission reductions and financial compensation of regions can be realised. The literature provides studies of many different burdensharing schemes which have been analysed over the past. An overview is compiled in Tavoni et al. (2013). This publication also explains the methodological background of two burden-sharing schemes that we use for our study. Tavoni et al. (2013) also provide the outcomes of the LIMITS cross-model comparison study on 
the two burden-sharing schemes. Further comparative assessments of different burden-sharing principles can be found, for instance, in den Elzen et al. (2008), Hof et al. (2008), Jacoby et al. (2008) and Ciscar et al. (2013).

Our study concerns two different burden-sharing schemes. The first scheme, which we refer to as "resource-sharing" scheme uses a population based indicator, and the second scheme, the so-called "effort-sharing" scheme, considers climate policy costs and economic development. The resource-sharing scheme describes an allocation mechanism for emission permits according to the level of GHG emissions allowed per capita. For this scheme we assume a transition phase for the period 2020-2050 in which the regional per capita emissions converge from statusquo towards the global average while the global average converges according to the GHG reduction obligation in order to achieve stringent climate targets. For an explanation of the terminology 'contraction and convergence' see Meyer (2000). The goal of the effort-sharing scheme is to equalise the mitigation costs across regions with the paradigm that all regions should incur the same climate change control costs in percentage terms of their GDP after emissions trading. Hence, revenues or expenses from carbon certificate trade are included in climate change control costs. Starting in 2020, the regions' shares of total climate change mitigation costs should be equal to the world average. This implies that regions with higher relative mitigation costs compared to the global average receive additional carbon certificates. Each region gains revenue from the carbon market through the sale of excess carbon certificates, which provides compensation (at least partly) for their mitigation costs. This effect leads to an equalisation of climate change mitigation efforts across regions. Conversely to contraction and convergence under the resource-sharing scheme, we assume no transition phase under the effort-sharing scheme.

The two burden-sharing schemes are investigated under a framework of stringent climate policy goals achieving a long-term stabilisation of the global mean temperature increase at $2{ }^{\circ} \mathrm{C}$ with respect to the pre-industrial level. For the calculation of the regional allowance allocation we apply a $2{ }^{\circ} \mathrm{C}$ climate stabilisation scenario in which the regional allocation of $\mathrm{GHG}$ emission certificates corresponds to the regional emissions under a global least-cost GHG reduction pathway. This scenario is referred to as the 'reference' scenario. In both burden-sharing schemes the amount of worldwide available emission allowances equals the reference scenario in each period. The duration of one trading period is 10 years while banking or borrowing between trading periods is not allowed.

The model implementation of the burden-sharing schemes, which is described in more detail in Kober et al. (2014), is realised through pre-optimisation procedures for the calculation each region's overall allocations of permits. The calculated certificate quantities are introduced as user constraints to the optimisation problem. Key input parameters for the calculation of the allocation of emission allowances under the resource-sharing scheme are the population development assumptions, the regional GHG emissions per capita in 2020 and the future evolution of the global average of per capita GHG emissions. For the calculation of the regional per capita emissions in 2020 and the global average specific emissions from 2020 
onwards, we used those derived from the reference scenario. Each regions' per capita emissions contract beyond their respective starting points in 2020 and converge in subsequent decades by 2050 . Under the effort-sharing scheme target policy costs are calculated for every region and period. These regional costs are the product of the world total climate change control costs as percentage of global GDP and the GDP of the respective region. The difference between all regions' effortsharing target policy costs and their policy costs under global least-cost climate change mitigation is divided by the global carbon certificate price for each period. The resulting quantity per period is added to the regions' emission levels calculated under least-cost mitigation criteria, which then equals the regional effort-sharing certificate allocation.

\section{Results}

We focus the presentation of our results on the time period to 2050. Nevertheless, long-term energy system effects past 2050 are considered in our study due to our model approach with perfect foresight for the time horizon until 2100.

\subsection{GHG Emissions Development and Associated Costs in the Reference Scenario}

The reference scenario is characterised through a GHG emissions reduction pathway with fragmented weak national climate policies in the near-term that reflect the unconditional Copenhagen pledges. For the period after 2020 we anticipate a global coordinated action to achieve climate stabilisation at $2{ }^{\circ} \mathrm{C}$ average atmospheric temperature increase, which is implemented through a maximum radiative forcing level of $2.8 \mathrm{~W} / \mathrm{m}^{2}$ in $2100 .^{3}$ A detailed description of the policy framework and assumptions of this scenario can be found in Kriegler et al. (2013).

The GHG emissions of the reference scenario are displayed for the 15 model regions disaggregated by emission source in Fig. 1. The development of the regional emissions in 2020 mimic the countries' Copenhagen pledges as described in Kriegler et al. (2013). Global level GHG emissions reach their maximum in 2020 with $51 \mathrm{GtCO}_{2} \mathrm{e}$ and decrease afterwards to $21 \mathrm{GtCO}_{2} \mathrm{e}$ in 2050 . Undoubtedly, industrialised countries and emerging economies have to reduce their GHG emissions drastically in order achieve the global $2{ }^{\circ} \mathrm{C}$ climate change control target at

\footnotetext{
3 This forcing target refers to all anthropogenic radiative agents with the exception of three agents: nitrate aerosols, mineral dust aerosols, and land use albedo changes. According to our model approach we adjusted the forcing target to be applied to the three GHG emissions represented in the TIAM-ECN.
} 


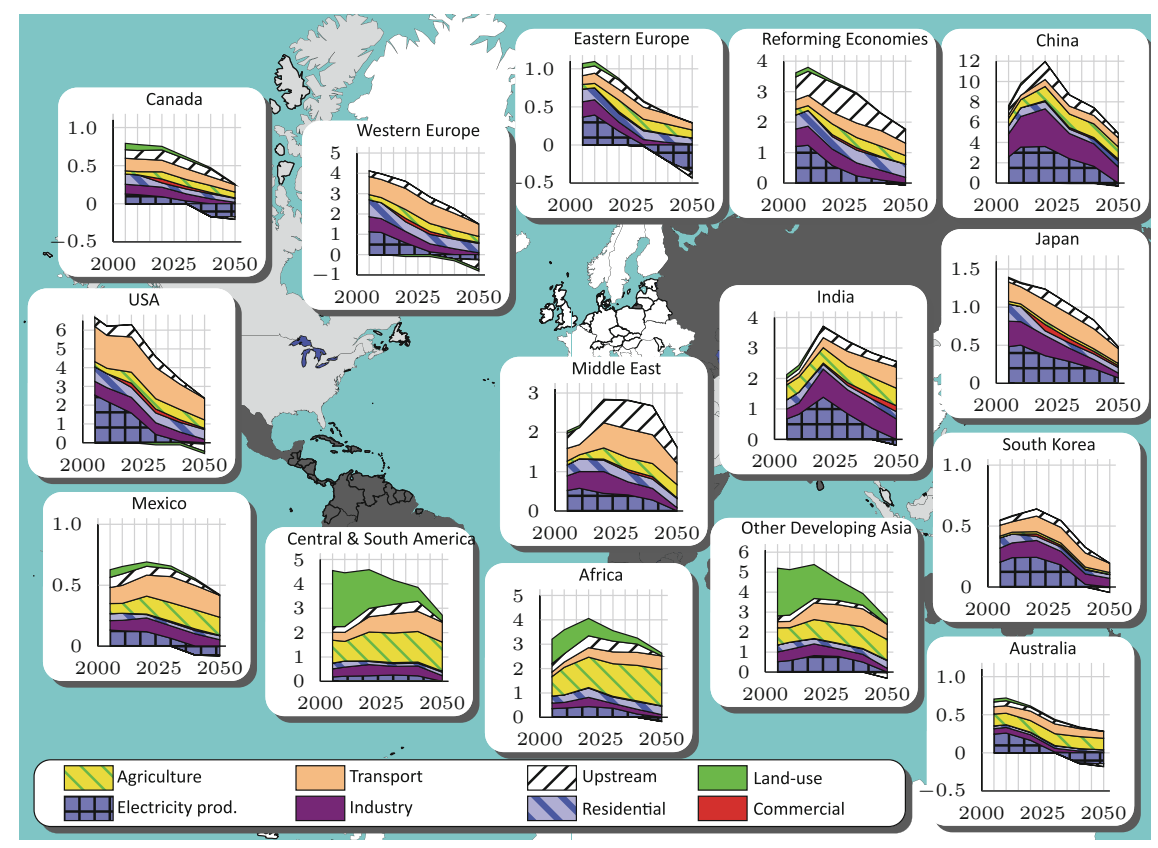

Fig. 1 GHG emissions by sector in the reference $2{ }^{\circ} \mathrm{C}$ climate change control scenario with leastcost long-term $\mathrm{GHG}$ mitigation (units in $\mathrm{GtCO}_{2} \mathrm{e}$ )

least costs. For most of the industrialised regions GHG emissions never exceed 2010 emission levels. Deepest emission reductions in relative terms are realised in Eastern and Western Europe, Canada and Australia where 2050 emission levels are at least $80 \%$ below 2010 emissions. In most of the non-OECD regions, which are characterised by either a strong economic growth and/or a significant increase of population, GHG emissions continue to increase until 2020 and decline rapidly afterwards. A modest increase of emissions in the two regions Central and South America and Other Developing Asia towards 2020 can be observed as a result of compensation of increasing emissions from fossil fuel combustion and agricultural activities by decreasing emissions from land-use and land-use change and forestry (LULUCF). The emissions from LULUCF follow a declining trend which can partly be attributed to policy measures due to the benefits related to conservation of natural area and biodiversity. There are only four out of the 15 regions with emission reductions in 2050 compared to 2010 of less than $40 \%$, which are Africa, Central and South America, India and the Middle East.

In general, we observe most of the GHG emission reductions being realised through abatement of $\mathrm{CO}_{2}$, in particular in the upstream sector and in the power sector which in some regions even allow for negative net emissions. Negative emissions occur when biomass is converted in technologies with carbon dioxide capture and storage (CCS), e.g. for the production of electricity, biofuels or hydrogen. For instance, in Eastern and Western Europe, the USA, Canada and 
Australia, negative GHG emissions of the electricity and upstream sectors offset emissions of sectors with more costly abatement options. Compared to the power sector and the upstream sector, GHG emission reductions in agriculture, e.g. for food production, and in the transport sector, are more expensive and in some cases have very limited mitigation potential. For insights in the global, regional and sectoral emission reductions and the deployment of low-carbon technology we refer to van der Zwaan et al. (2013b), Calvin et al. (2013) and van Sluisveld et al. (2013) who provide their findings in the light of the same scenario framework as presented in this publication. In our study we assume a broad availability of GHG mitigation measures, such as renewable energy, CCS technology and alternative fuel conversion technologies in the demand sectors that are necessary to realise the transition to a decarbonised energy system. Future technology deployment is associated with a various uncertainties which have been investigated by van der Zwaan et al. (2013b) related to the availability and cost of low-carbon technology, and by Keppo and van der Zwaan (2012) related to CCS technology in particular.

Looking at the regions' specific per capita emissions, displayed in the left panel in Fig. 2, this indicator is highest in 2020 in Australia, Canada and the USA with around $20 \mathrm{MtCO}_{2} \mathrm{e} / \mathrm{capita}$ and lowest in Africa and India with $3 \mathrm{MtCO}_{2} \mathrm{e} / \mathrm{capita}$, while on global average $7 \mathrm{MtCO}_{2} \mathrm{e}$ are emitted per capita in 2020. The global average per capita emission declines to $2 \mathrm{MtCO}_{2} \mathrm{e} /$ capita in 2050. This global average in 2050 represents the convergence target for the emission allocation under the resource-sharing scheme. The regional per capita emissions in 2050 range from $6 \mathrm{MtCO}_{2} \mathrm{e}$ per capita for Reforming Economies to less than zero for Eastern Europe.

The carbon certificate price that corresponds to the emission trajectory in order to attain the $2{ }^{\circ} \mathrm{C}$ climate target increases from $70 \mathrm{US} \$ / \mathrm{tCO}_{2} \mathrm{e}$ in 2020 to

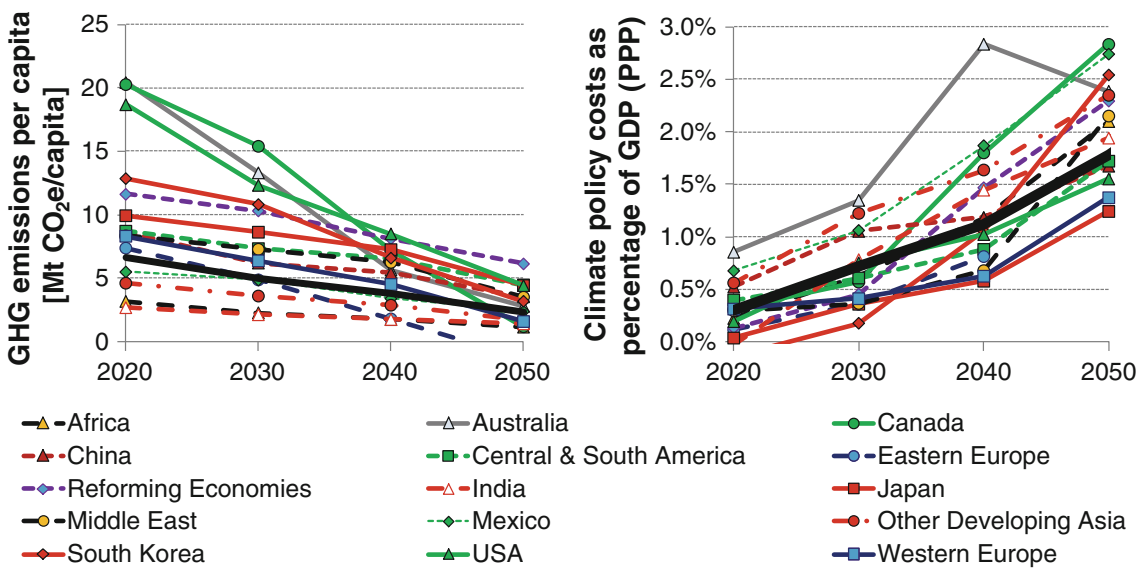

Fig. 2 Regional GHG emissions per capita (left panel) and GHG emission intensity of GDP (right) in the reference $2{ }^{\circ} \mathrm{C}$ climate policy scenario 
$130 \mathrm{US} \$ / \mathrm{tCO}_{2} \mathrm{e}$ in 2030 , and to $390 \mathrm{US} \$ / \mathrm{tCO}_{2} \mathrm{e}$ in 2050 . According to our model approach, this price path represents the marginal overall GHG emission abatement cost, and it applies to all regions and sectors of the global energy system. In 2020 the certificate prices are strongly influenced by the stringent Copenhagen/Cancun pledges we imposed, and prices in the long-run are determined by the availability and cost of the GHG mitigation measures. These abatement prices are in line with the prices stated by other models which span a range between 200 and 900 US\$/ $\mathrm{tCO}_{2} \mathrm{e}$ in 2050 with a median at $200 \mathrm{US} \$ / \mathrm{tCO}_{2} \mathrm{e}$ (see Kriegler et al. 2013). The Global Energy Assessment reports a $\mathrm{CO}_{2}$ price above $110 \mathrm{US} \$ / \mathrm{tCO}_{2} \mathrm{e}$ that is associated with a global GHG emission reduction down to about $25 \mathrm{GtCO}_{2} \mathrm{e}$ by 2040 (GEA 2012). The worldwide aggregated energy system costs (including costs to avoid non-energy related GHG emissions), to which we refer as 'climate policy costs', accumulate to 77 trillion US\$ for the entire first half of the century with 0.3 trillion US\$ in 2020, and around 4 trillion US\$ in 2050. In 2020, the highest costs occur in China (90 billion US\$), followed by Western Europe (50 billion US $\$)$. For India in 2020 we observe a slightly positive cost effect due to reduced fossil energy imports under climate policy. In absolute terms, China faces highest climate policy costs throughout the whole first half of the century, with about one fifth of the global costs in 2050, and India's costs grow substantially in this timeframe that India becomes the country second highest climate policy costs by 2050 (16\% of the global costs).

For the effort-sharing scheme of particular importance, we provide the climate policy costs in relative terms to GDP in the right panel in Fig. 2, which shows that these costs on global level correspond to $0.3 \%$ in 2020 and $1.7 \%$ in 2050 . Australia faces comparably high costs until 2040 due to the fact that the country undergoes a substantial change of its domestic energy supply structure and its revenues from coal export decline drastically as a result of reduced coal demand under climate change policy. After 2030/2040 this effect applies also to the Middle East, Reforming Economies and Canada, which experience extensive net fossil fuel exports under absence of climate policy and possess few local GHG reduction potential. Under stringent climate policy their fossil fuel exports reduce significantly in the long-run associated with a decline of their revenues from the oil and gas markets, which consequently leads to an increase of their climate policy costs. In China until 2030 and in Mexico and Other Developing Asia over the whole period, relative policy costs are higher than the world average, which results from the large expected increases in their respective energy demands and thus massive investment requirements in renewable energy for power production and energy efficiency improvements on the demand side. Western Europe and Japan are

\footnotetext{
${ }^{4}$ Policy costs in the context of our bottom-up modelling approach refer to undiscounted costs for the entire energy system, including expenditures for technology investments, operation and maintenance, other variable costs as well as costs associated with changing demand patterns. Policy implementation and transaction costs are excluded. Climate policy costs are calculated as the difference between the total costs under certain policy conditions and the costs in the reference case.
} 
regions with relative climate policy costs below the global average for most of the time until 2050, which is driven by their low energy intensity of GDP, their reduction of energy imports under climate change policy and their good potentials to deploy low-carbon technology. This includes for both regions the continuation of electricity production from nuclear power until 2050 with an installed power plant capacity at around 2005 level.

\subsection{Allocation of Emission Allowances}

Based on the development of GHG emissions in the reference scenario and the burden-sharing schemes' calculation methods, regional allowance endowments are determined as displayed in Fig. 3. Independent of the burden-sharing scheme China is the region which receives most of certificates equivalent to cumulative emissions for the period 2020-2050 of about $250 \mathrm{GtCO}_{2} \mathrm{e}$. The figure also illustrates that for the majority of the regions the allocation according to the effort-sharing deviates less from the regions' cost-optimal GHG emission trajectories than the distribution under the resource-sharing scheme.

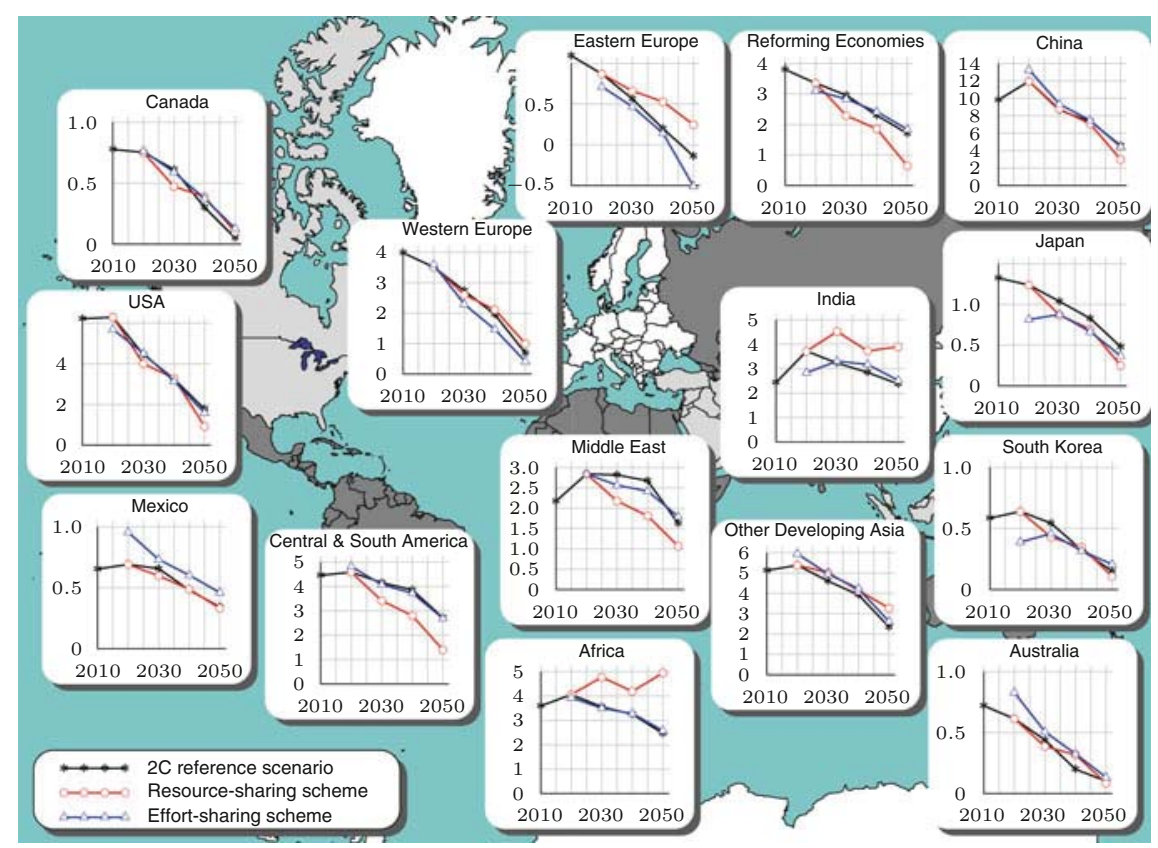

Fig. 3 GHG emissions in the reference scenario and emission allowances allocation under the two burden-sharing regimes (units in $\mathrm{GtCO}_{2} \mathrm{e}$ ) 
The resource-sharing method favours regions with a high population growth, such as Africa and India. For both regions the amount of emission permits increases from 2020 to 2030, and for Africa also from 2040 to 2050. All other regions receive less certificates in the periods past 2020. The endowment of certificates to Other Developing Asia is higher than the emission reductions of the reference pathway as a result of the initially low per capita emissions in 2020 and the high population growth in this region. In regions with low or even negative population growth rates, the number of emission rights of regions declines drastically in particular when the initial number of GHG emissions allowances is high, such as for China, Japan, the USA, Central and South America and Reforming Economies.

The effort-sharing scheme favours regions which are characterised by comparably high costs for GHG emission reduction with respect to their overall economic capability. China receives emission permits between 2020 and 2050 of cumulatively $256 \mathrm{GtCO}_{2} \mathrm{e}$, which exceeds the reference GHG emissions by $14 \mathrm{GtCO}_{2} \mathrm{e}$ (6\%). Also Other Developing Asia, Mexico and Australia can profit from additionally available certificates worth about $18 \mathrm{GtCO}_{2} \mathrm{e}$ until 2050. In contrast, Western Europe and Japan as a region with a high expected GDP and moderate climate policy costs get $16 \mathrm{GtCO}_{2} \mathrm{e}$ less allocated in the same timeframe compared to its reference emission pathway.

When comparing the certificate allocation under the two burden-sharing schemes, significant differences can be observed for Africa, India, Latin America, the Middle East and Reforming Economies. Africa, for example, receives under the resource-sharing allocation in total $34 \mathrm{GtCO}_{2} \mathrm{e}$ more emission permits until 2050 than under the effort-sharing scheme. The different endowments affect the carbon certificate trade and hence the extent to which the regions are compensated for their climate change mitigation efforts.

\subsection{Carbon Certificate Trade}

Emission certificate trade allows a return from an initial certificate allocation to the overall cost-optimal mitigation pathway, if one assumes the existence of a perfect carbon certificate market (as we here do). The traded quantities are determined by the allocation of GHG emission rights and the region's technological potentials to reduce GHG emissions. The trade of certificates in the resource-sharing scheme starts after the year of grandfathering in 2020. A cumulative amount of certificates equivalent to $83 \mathrm{GtCO}_{2} \mathrm{e}$ is traded until 2050 under the resource sharing scheme. $60 \%\left(50 \mathrm{GtCO}_{2} \mathrm{e}\right)$ less certificates are traded under the effort-sharing scheme in the same period due to the fact, that the allocation under the effortsharing regime comes closer to each regional cost-optimal GHG emissions reduction pathways than under the resource sharing scheme.

Under the resource-sharing regime the total annually traded quantity of emission rights reaches its maximum with $6 \mathrm{GtCO}_{2} \mathrm{e}$ in 2050, which represents about a quarter of the global GHG emissions and half of the global $\mathrm{CO}_{2}$ emissions in that 
year. Most of the emission certificates are sold by Africa and India (Table 1). These two regions combined sell emission rights equivalent to a cumulative amount of $63 \mathrm{GtCO}_{2} \mathrm{e}$ until 2050, which corresponds to about $80 \%$ of all certificates sold in this period. Around $80 \%$ of the tradable permits in this time frame are bought by Central and South America, China, the Middle East and the Reforming Economies due to their rapidly increasing GHG emissions and modest or even negative population growth rates.

Table 1 Emission certificate trade and carbon market capital flow cumulative between 2020 and 2050 for the two burden-sharing schemes

\begin{tabular}{|c|c|c|c|c|c|}
\hline \multicolumn{3}{|c|}{ Resource-sharing scheme } & \multicolumn{3}{|c|}{ Effort-sharing scheme } \\
\hline & $\begin{array}{l}\text { Certificates } \\
\text { sold } \\
\left(\mathrm{MtCO}_{2} \mathrm{e}\right)\end{array}$ & $\begin{array}{l}\text { Revenues from } \\
\text { the carbon market } \\
\text { (billion US\$) }\end{array}$ & & $\begin{array}{l}\text { Certificates } \\
\text { sold } \\
\left(\mathrm{MtCO}_{2} \mathrm{e}\right)\end{array}$ & $\begin{array}{l}\text { Revenues from } \\
\text { the carbon market } \\
\text { (billion US\$) }\end{array}$ \\
\hline \multicolumn{6}{|c|}{ Certificate selling regions } \\
\hline Africa & 33984 & 8473 & China & 13873 & 1327 \\
\hline India & 29375 & 6574 & $\begin{array}{l}\text { Other Dev. } \\
\text { Asia }\end{array}$ & 10620 & 1831 \\
\hline $\begin{array}{l}\text { Other Dev. } \\
\text { Asia }\end{array}$ & 10937 & 2809 & Mexico & 3883 & 693 \\
\hline $\begin{array}{l}\text { Eastern } \\
\text { Europe }\end{array}$ & 6233 & 1614 & Australia & 3171 & 505 \\
\hline $\begin{array}{l}\text { Western } \\
\text { Europe }\end{array}$ & 1870 & 797 & Canada & 951 & 290 \\
\hline \multirow[t]{2}{*}{ Australia } & 586 & 165 & India & 366 & 788 \\
\hline & 82984 & 20432 & & 32865 & 5435 \\
\hline \multicolumn{6}{|c|}{ Certificate buying regions } \\
\hline $\begin{array}{l}\text { South } \\
\text { America }\end{array}$ & -24549 & -5854 & $\begin{array}{l}\text { Western } \\
\text { Europe }\end{array}$ & -10272 & -2151 \\
\hline $\begin{array}{l}\text { Middle } \\
\text { East }\end{array}$ & -17850 & -3823 & Japan & -5899 & -936 \\
\hline $\begin{array}{l}\text { Ref. } \\
\text { Economies }\end{array}$ & -16432 & -3905 & USA & -4461 & -760 \\
\hline China & -9632 & -3605 & $\begin{array}{l}\text { Middle } \\
\text { East }\end{array}$ & -4207 & -553 \\
\hline USA & -8403 & -2150 & \begin{tabular}{|l|} 
Eastern \\
Europe
\end{tabular} & -4139 & -1022 \\
\hline Japan & -4146 & -953 & $\begin{array}{l}\text { South } \\
\text { Korea }\end{array}$ & -1902 & -106 \\
\hline $\begin{array}{l}\text { South } \\
\text { Korea }\end{array}$ & -1119 & -174 & $\begin{array}{l}\text { South } \\
\text { America }\end{array}$ & -1087 & -366 \\
\hline Mexico & -569 & -79 & $\begin{array}{l}\text { Ref. } \\
\text { Economies }\end{array}$ & -627 & 272 \\
\hline \multirow[t]{2}{*}{ Canada } & -283 & 112 & Africa & -273 & 186 \\
\hline & -82983 & -20432 & & -32866 & -5435 \\
\hline
\end{tabular}


Associated to the trade of emission allowances is the capital transfer on the global carbon market, which is determined by the amount of certificates traded and the corresponding price of emission certificates. As a result of the exponential increase of the carbon certificate price, the carbon market capital flow is increasingly determined by the certificate price, rather than by the traded quantities. Under the resource-sharing scheme the total carbon market capital flow accumulates to 20 trillion US\$ until mid of this century with annual capital transfers of 400 billion US\$ in 2030 to 620 billion US\$ in 2040 and to 2200 billion US\$ in 2050 (Table 1). Over the entire timeframe Africa and India receive together $70 \%$ of the worldwide generated revenues from sales of certificates. Conversely, Central and South America's spends about $30 \%$ of the total global expenditures for certificate purchases, and the Middle East, Reforming Economies and China about $20 \%$ each.

Comparing the global capital flows of the carbon certificate market under the resource-sharing scheme with the climate policy costs associated with the $2{ }^{\circ} \mathrm{C}$ climate stabilisation target, reveals, that the cumulative carbon market capital flows represent $30 \%$ of the global policy costs during the first half of the 21 st century (Fig. 4). Of course, this indicator deviates regionally. For the group of non-OECD countries, in total $4 \%$ of the policy costs can be compensated by revenues from the carbon market until 2050. Looking at single regions, we can observe for Africa on the one hand total cumulative revenues from the carbon market of 8.5 trillion US\$ which is almost 2.5 times the cumulative climate policy costs ( 3 trillion US\$) in the

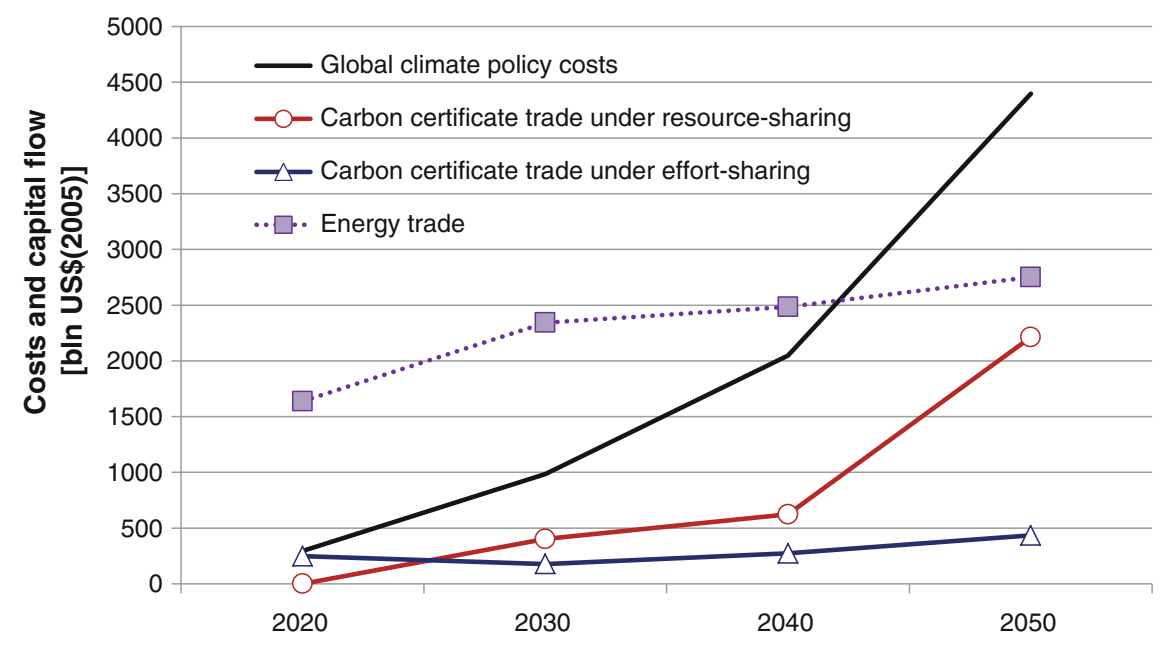

Fig. 4 Climate policy costs and capital flows for trade of carbon certificates, energy and captured $\mathrm{CO}_{2}$ under the resource-sharing scheme (based on Kober et al. 2014) N.B. Capital flows refer to trade among the 15 regions represented in the model. Market capital volumes would increase if results are shown based on a higher geographical resolution 
period to 2050. On the other hand, Reforming Economies' expenses for certificate purchases are about $50 \%$ higher than their climate policy costs in the reference scenario for the period 2020 to 2050. These two cases indicate that the resourcesharing regime analysed in this study is unsuitable to compensate all developing and transition countries at once. This underpins the drawback of the resourcesharing scheme, which refers to the allocation regardless of each region's capabilities to reduce GHG emissions. Especially, if a regions' population growth is rather moderate, or even negative, and emission abatement measures are costly, the region is hardly compensated for their cost to mitigate climate change. The case of Africa also shows that the resource-sharing scheme might also over-compensate the financial efforts of GHG emission reduction measures of selected emerging regions. This finding has also been observed by Jacoby et al. (2008).

Under the effort-sharing scheme certificate trade reaches its maximum with almost $3 \mathrm{GtCO}_{2} \mathrm{e}$ in 2020 and declines in the subsequent periods until 2050 to about $1 \mathrm{GtCO}_{2} \mathrm{e}$ annually. The resulting annual carbon market volume ranges between 170 and 270 billion US\$ in the period 2020 until 2040 and peaks at 430 billion US\$ in 2050. The corresponding cumulative capital flow until 2050 (5 trillion US\$) represents one quarter of the volume under the resource-sharing scheme. China and Other Developing Asia are prime certificate selling regions under the effort-sharing regime, and receive 30 and $40 \%$ respectively of the total global carbon market revenues until 2050. China is particular important in the near-term with a share of global certificate sales values of $50 \%$ in 2020 (95 billion US\$). In the decades beyond 2020, China's carbon market revenues decline, and towards mid-century China's position on the market changes from a net selling region to a net buying region. The main selling regions in 2050 are Other Developing Asia, the Middle East, Reforming Economies and India, which receive each more than 50 billion US $\$$. Western Europe is by far the main buyer of emission certificates with cumulative expenditures of 2.2 trillion US\$ in the first half of this century and a maximum annual capital requirement of 110 billion US\$ in 2050. Eastern and Western Europe combined spent up to 250 billion US\$ in 2050 for purchases of permits, and hence for compensation of other regions for their climate change control costs.

The capital volume of the carbon certificate market as percentage of the global climate policy costs is about $10 \%$ for the period 2020-2050 under the effortsharing regime. The development of this share over time reveals a declining trend from $70 \%$ in 2020 to $10 \%$ in 2050. Comparing these global shares, with those of the resource-sharing scheme, however, is insufficient to assess both burden-sharing schemes with regard to their ability to reach a fairer distribution of the region's costs for mitigating climate change. Our model results show significant regional differences between the two burden-sharing schemes with respect to the regions revenues or expenditures on the carbon market versus their climate policy costs. In 2020, China and Central and South America are able to recover almost all their climate policy costs through revenues from the carbon market, and Other Developing Asia at least $30 \%$. Overcompensation, as observed for Africa under the resource-sharing scheme, is less significant under the effort-sharing regime. The effort-sharing regime allows all non-OECD countries combined, to cover $12 \%$ of 
their climate policy costs using revenues from the carbon certificate market during the first half of the century, with a maximum of $27 \%$ in 2020 and a minimum of $9 \%$ in 2040. Comparing the two burden-sharing schemes we conclude, that the effort-sharing regime is better capable to compensate less developed economies for their costs under a global $2{ }^{\circ} \mathrm{C}$ climate policy framework. The effect of burdensharing - generating generally higher policy costs for the cluster of OECD countries and lower ones for non-OECD countries - is larger for the effort-sharing scheme than the resource-sharing scheme.

The certificate exchanges and associated capital volumes to realise either of the two burden-sharing schemes indicate the importance of the existence of an appropriate carbon certificate market to cost-efficiently reach climate change mitigation goals. In particular under the resource-sharing scheme, the capital transfer of the carbon market would almost reach the level of energy market capital flows around the middle of the century (Fig. 4). For the assessment presented here we assumed perfectly functioning markets for both carbon certificates and energy commodities. It might be difficult, to establish perfect carbon market conditions, and market distortions of many different types could arise. For an analysis of the impacts of an imperfect carbon certificate trade we refer to Kober et al. (2014), who investigate in particular effects related to timing issues, regional trade implications, certificate price effects, and global climate policy costs.

\section{Conclusions}

In this study we analysed the two different regional burden-sharing schemes for the allocation of GHG emission allowances, the resulting carbon certificate trade, and carbon market capital flows under a $2{ }^{\circ} \mathrm{C}$ climate policy regime. To achieve this climate target at least-cost, global GHG emissions must reduce by half between 2010 and 2050, which is in line with recent publications (see Kriegler et al. 2013; IPCC 2014; IEA 2014). Thereby sectors in which abatement is costly, such as agriculture, industry and transportation, would be compensated by extensive emissions reductions in other sectors which even become negative net emitters in selected regions around the middle of the century.

We investigated a population-based certificate allocation regime (resourcesharing) versus a scheme which aims at equal distribution of the economic burden across regions (effort-sharing). We find that under the resource-sharing regime the regional allocation of emission certificates deviates more from the region's emission trajectories under a global least-cost reference mitigation pathway than observed under the effort-sharing scheme. Consequently, significant differences between the two burden-sharing schemes occur regarding the amount of certificates traded on a global certificate market, and the resulting carbon market capital flow. Between 2020 and 2050 under the resource-sharing scheme almost three times more certificates are traded than under the effort-sharing scheme. Establishing a proper functioning of a global carbon certificate market is essential when implementing 
burden-sharing schemes, as it allows the unlocking of a regions' least cost GHG mitigation potential. If carbon certificate trade possibilities are limited global costs to attain the $2{ }^{\circ} \mathrm{C}$ climate target might even increase by $20 \%$ (Kober et al. 2014).

The resource-sharing method favours regions with a high population growth, such as Africa and India. Both regions are net seller of certificates on the certificate market with cumulative sales of permits equivalent to $63 \mathrm{GtCO}_{2} \mathrm{e}$ until 2050 which corresponds to an aggregated capital flow of 15 trillion US\$. With these revenues from the carbon market, both regions combined can cover their climate policy costs until 2050. The most important certificate-buying regions until 2050 are Central and South America, the Middle East, Reforming Economies and China due to their low or even negative population growth.

The effort-sharing scheme favours regions which are characterised by comparably high costs for GHG emission reduction with respect to their overall economic capability. China and Other Developing Asia face comparable high climate policy costs in the near-term and receive excess emission permits which they sell on the carbon market and gain combined revenues worth 140 US\$ in 2020. These revenues offset the regions' climate policy costs in that year. Towards 2050 China becomes a net buying region as a result of its strong economic growth and comparable advantage in terms of its GHG emissions reduction potential. An important determinant of climate policy costs in the long-run are changes in fossil fuel trade, which occur as consequence of global fuel shifts towards low-carbon energy and demand reductions to meet the stringent climate targets. This increases climate policy costs of traditional fossil fuel exporting regions (Middle East, Reforming Economies and Australia) because of substantial reductions of their import revenues from fossil fuel trade. Western Europe, which has relatively low climate policy costs as percentage of its GDP, is the main buyer of emission certificates with cumulative expenditures of 2.2 trillion US\$ in the first half of this century and a maximum annual capital requirement of 110 billion US\$ in 2050.

Comparing both burden-sharing schemes, with regard to the compensation of non-OECD countries' climate change mitigation efforts via revenues from the global carbon certificate market, reveals an advantage of the effort-sharing scheme over the resource-sharing scheme. Under the effort-sharing regime, for all nonOECD countries combined, about $12 \%$ of their climate policy costs can be covered by revenues from the carbon certificate market during the first half of the century, with a maximum of $27 \%$ in 2020 . The average annual capital needed to realise this compensation until 2050 amounts to about 140 billion US\$. Comparing these means, with the 100 billion US $\$ 2020$ targeted to be mobilized by the Green Climate Fund under the Copenhagen accord by 2020, (UNFCCC 2014) advocates for continuation of this financial instrument in future and to increase its budget, if a higher compensation of less developed economies is aimed for. 


\section{References}

Calvin K, Wise M, Klein D, McCollum D, Tavoni M, van der Zwaan B, van Vuuren D (2013) A multi-model analysis of the regional and sectoral roles of bioenergy in near-term and long-term carbon mitigation. Clim Change Econ 4(4):1-31

Ciscar J, Saveyn B, Soria A, Szabo L, van Regemorter D, van Ireland T (2013) A comparability analysis of global burden sharing GHG reduction scenarios. Energy Policy 55:73-81

den Elzen M, Höhne N, van Vliet J, Ellerman C (2008) Exploring comparable post-2012 reduction efforts for AnnexI countries. MNP report 500102019/2008, Netherlands Environmental Assessment Agency (MNP), Bilthoven

European Union (2013) Decision of the European parliament and of the council on the effort of Member States to reduce their greenhouse gas emissions to meet the Community's greenhouse gas emission reduction commitments up to 2020. 406/2009/EC

GEA (2012) Global energy assessment - towards a sustainable future. Cambridge University Press, Cambridge

Hof A, den Elzen M, van Vuuren D (2008) Environmental effectiveness and economic consequences of fragmented versus universal regimes: what can we learn from model studies? Int Env Agreements: Politics, Law Econ 9(1):39-62

IEA (2014) Energy technology perspectives. International Energy Agency, Paris

IPCC (2014) Climate change 2014: mitigation of climate change. In: Edenhofer O, Pichs-Madruga R, Sokona Y, Farahani E, Kadner S, Seyboth K, Adler A, Baum I, Brunner S, Eickemeier P, Kriemann B, Savolainen J, Schlömer S, von Stechow C, Zwickel T and Minx JC (eds) Contribution of working group III to the fifth assessment report of the intergovernmental panel on climate change. Cambridge University Press, Cambridge, United Kingdom and New York, NY, USA

Jacoby H, Babiker M, Paltsev S, Reilly J (2008) Sharing the burden of GHG reductions. Report No. 167, MIT joint program on the science and policy of global change, Cambridge, MA, USA

Keppo I, van der Zwaan B (2012) The impact of uncertainty in climate targets and $\mathrm{CO}_{2}$ storage availability on long-term emissions abatement. Environ Model Assess 17:177-191

Kober T, van der Zwaan B, Rösler H (2014) Regional burden sharing regimes for reaching a global long-term $2{ }^{\circ} \mathrm{C}$ climate change control target. Clim Change Econ 5(1):0-32

Kriegler E, Tavoni M, Aboumahboub T, Luderer G, Calvin K, De Maere G, Krey V, Riahi K, Rösler H, Schaeffer M, van Vuuren D (2013) What does the $2{ }^{\circ} \mathrm{C}$ target imply for a global climate change agreement in 2020? The LIMITS study on implications of Durban platform action scenarios. Clim Change Econ 4(4):1-30

Meyer A (2000) Contraction and convergence - the global solution to climate change. Schumacher Briefings 5, Green books for the Schumacher society, Bristol, USA

Phylipsen, D, Blok C (2013) European experiences with burden sharing in climate changelessons learned for the post-2020 negotiations. Report published under the MAPS programme

Rösler, H, Bruggink J, Keppo I (2011) Design of a European sustainable hydrogen model - model structure and data sources. Energy research Centre of the Netherlands (ECN) report ECN-E-11041, Petten

Rösler H, van der Zwaan B, Keppo I, Bruggink J (2014) Electricity versus hydrogen under stringent climate change control. Sustain Energy Technol Assess 5:106-118

Tavoni M, Kriegler E, Aboumahboub T, Calvin K, De Maere G, Jewell J, Kober T, Lucas P, Luderer G, McCollum D, Marangoni G, Riahi K, van Vuuren D (2013) The distribution of the major economies' effort in the Durban platform scenarios. Clim Change Econ 4(4):0-25

United Nations (UN) (2011) World population prospects: the 2010 revision. http://www.un.org/en/ development/desa/population/. Accessed 31 Mar 2012

UNFCCC (2014) Financial, technology and capacity-building support. http://cancun.unfccc.int/ financial-technology-and-capacity-building-support/new-long-term-funding-arrangements/. Accessed 31 July 2014 
van der Zwaan B, Keppo I, Johnsson F (2013a) How to decarbonize the transport sector? Energy Policy 61:562-573

van der Zwaan B, Rösler H, Kober T, Aboumahboub T, Calvin K, Gernaat D, Marangoni G, McCollum D (2013b) A cross-model comparison of global long-term technology diffusion under a $2{ }^{\circ} \mathrm{C}$ climate change control target. Clim Change Econ 4(4):1-24

van Sluisveld M, Gernaat D, Otto A, Isaak M, van Vuuren D, Mouratiadou I, Ashina S, Garg A, Shukla P, Calvin K, Rao S, Lucas P, van Vliet J (2013) A multi-model analysis of post-2020 mitigation efforts of five major economies. Clim Change Econ 4(4):1-24 